\title{
The lens in hereditary hyperferritinaemia cataract syndrome contains crystalline deposits of L-ferritin
}

Andrew D Mumford, Ian A Cree, Jayantha D Arnold, Myles C Hagan, Kenneth C Rixon, John J Harding

Haemostasis Research Group, MRC Clinical Sciences Centre, Imperial College School of Medicine, Hammersmith Hospital, Du Cane Road, London W12 0NN

A D Mumford

Department of Pathology, Institute of Ophthalmology, University College London, Bath Street, London, EC1V 9EL I A Cree

Department of Gastroenterology, Ealing Hospital, Uxbridge Road, Middlesex, UB1 3HW J D Arnold

Department of Ophthalmology, Ashford Hospital, London Road, Middlesex, TW15 3AN M C Hagan

Nuffield Laboratory of Ophthalmology, Walton Street, Oxford OX2 6AW

K C Rixon

J J Harding

Correspondence to: Professor J J Harding, Nuffield Laboratory of Ophthalmology, Walton Street, Oxford OX2 6AW john.harding@, ophthalmology.oxford.ac.uk

Accepted for publication 24 February 2000

\begin{abstract}
Backgroundlaim-Hereditary hyperferritinaemia cataract syndrome (HHCS) is an autosomal dominant disorder characterised by elevated serum L-ferritin and bilateral cataracts. The ocular manifestations of this disorder are poorly studied. This study therefore sought to determine the origin of cataracts in HHCS.

Methods-L-ferritin ELISA, immunohistochemical and ultrastructural analysis of a lens nucleus from an HHCS individual.

Results-The HHCS lens L-ferritin content was $147 \mu \mathrm{g} / \mathrm{g}$ dry weight of lens compared with $<16 \mu \mathrm{g} / \mathrm{g}$ for a non-HHCS control cataract lens. The cataract comprised discrete crystalline inclusions with positive staining with anti-L-ferritin but not anti-H-ferritin.

Conclusions-This unusual finding of crystalline opacities in the lens may be unique to HHCS and is likely to result from disturbed metabolism of $L$-ferritin within the lens or an abnormal interaction between $\mathrm{L}$-ferritin and lens proteins.

(Br F Ophthalmol 2000;84:697-700)
\end{abstract}

Ferritin in human tissues exists as a 24 -mer protein containing variable proportions of $21 \mathrm{kD}$ $\mathrm{H}$-chains and $19 \mathrm{kD}$ L-chains. Ferritin is an intracellular iron storage protein protecting tissues from oxidative damage by sequestration, oxidation, and nucleation of free iron in a central cavity. ${ }^{12}$ Both $\mathrm{L}$-ferritin and $\mathrm{H}$-ferritin genes contain a highly conserved sequence in the 5 '-untranslated region that encodes a cis acting regulatory sequence in the m-RNA termed the iron responsive element (IRE). The IRE interacts with an inhibitory trans acting cytoplasmic iron binding protein, the iron regulatory peptide (IRP), so that when intracellular iron concentrations are low, translation of the ferritin mRNA is prevented. Conversely, when iron concentrations increase, IRE-IRP binding is disrupted and ferritin synthesis proceeds. ${ }^{1}$

Disturbed regulation of $\mathrm{L}$-ferritin synthesis occurs in families with the recently recognised hereditary hyperferritinaemia cataract syndrome (HHCS). ${ }^{3-7}$ Affected individuals show heterozygous point mutations or deletions within the L-ferritin IRE and the resultant changes in the secondary structure of the IRE may prevent efficient interaction with the IRP. L-ferritin synthesis is then not subject to the normal inhibitory influence of the iron de- pendent IRP. The characteristic phenotype of this disorder is a fivefold to 20 -fold increase in serum L-ferritin concentration and the development of sutural lens opacities. Even in the more severely affected individuals, a greatly increased rate of ferritin synthesis is not associated with abnormal iron metabolism and the only demonstrable clinical abnormality is the formation of cataracts. The mechanism of formation of cataracts in affected individuals is unknown.

In this report we describe the biochemical and histological analysis of lens tissue from an individual with a severe HHCS phenotype and demonstrate that the lens contains crystalline deposits of immunoreactive L-ferritin.

\section{Patients and methods}

CASE REPORT

The 53 year old woman was identified as part of an 11 member family spanning three generations with HHCS. Six individuals showed the HHCS phenotype with cataracts and serum ferritin concentrations ranging from 902-1452 $\mu \mathrm{g} / 1$ (normal range 15-250 $\mu \mathrm{g} / \mathrm{l}$ ). Affected individuals were heterozygous for a A to $G$ point mutation in the L-ferritin m-RNA at position +40 relative to the translation start site (Paris-1 mutation).

Five affected individuals underwent ocular examination. Fine anterior and posterior sutural opacities were identified in a 10 month old individual and other family members, these appeared to increase in density with the increasing age of the individual (Fig 1). In the adults, the cortical opacities were more promi-

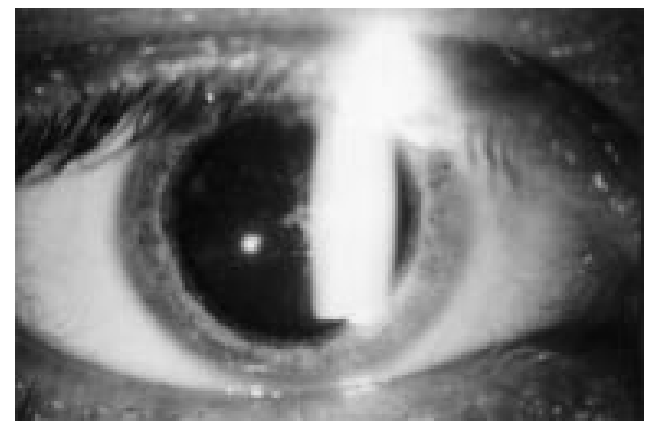

Figure 1 Slit lamp appearance of the lens from the proband. The cataract is visible as a central sutural opacity within the lens with additional cortical opacities visible extending radially. In the adults, the cortical opacities were more prominent near the lens equator but extending axially with increasing age. No other ocular abnormalities were demonstrated. The sequence of sutural opacities followed by radiating cortical opacity was reminiscent of the appearance of cataracts developing in diabetic rats. ${ }^{8}$ 

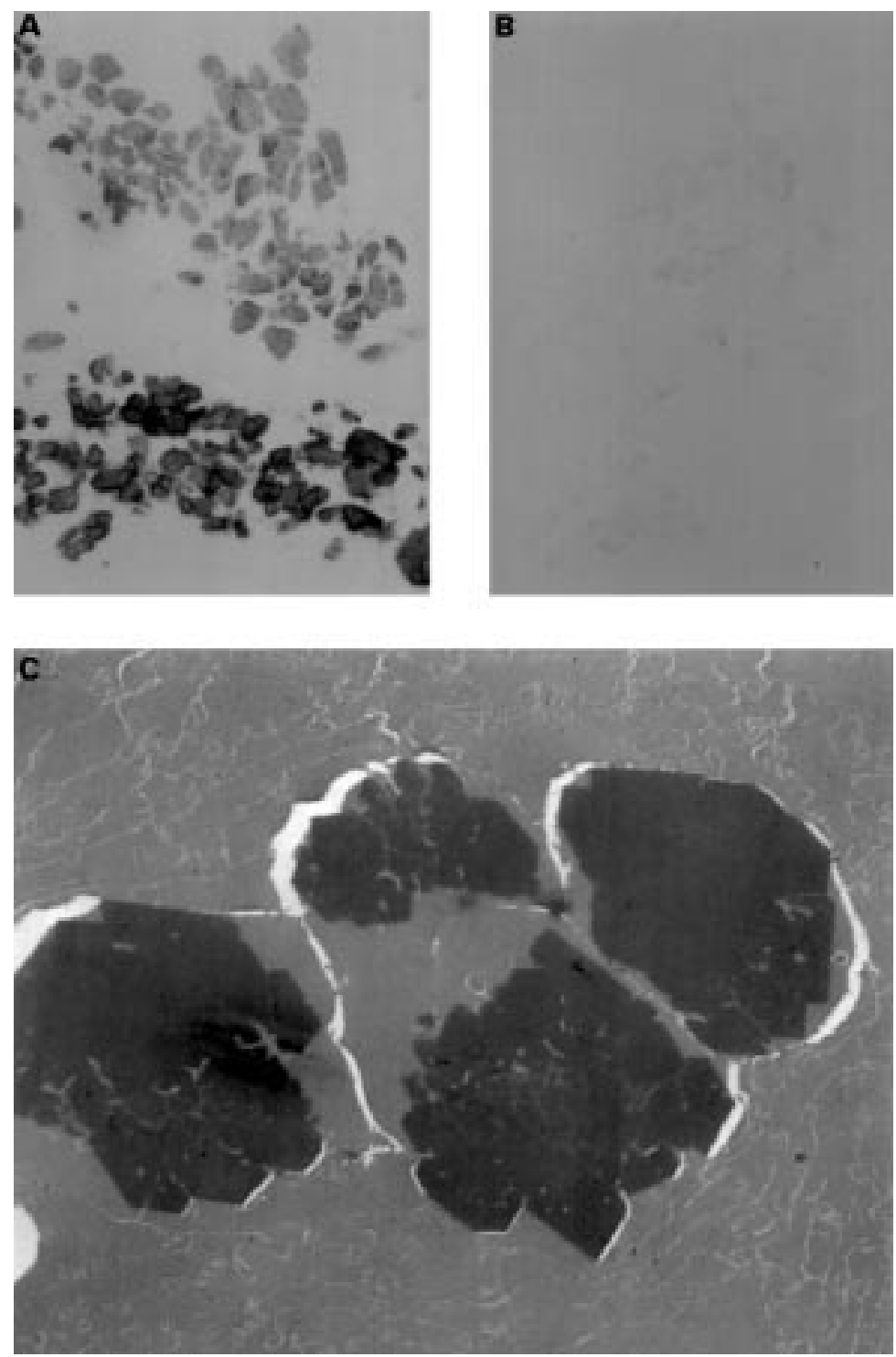

Figure 2 (A) Light microscopic appearance of crystalline inclusions within the lens stroma showing dense staining with monoclonal anti-L-ferritin $(\times 400)$. Staining was absent from the lens stroma itself. (B) The deposits were not stained with anti-H-ferritin $(\times 400) .(C)$ Appearance of inclusions at $\times 50000$ magnification showing square-shaped crystal morphology. The crystals were not associated with any cellular elements, but appeared to lie free within the stroma. coating buffer ( $35 \mathrm{mM}$ sodium bicarbonate, 15 $\mathrm{mM}$ sodium carbonate $\mathrm{pH} 9.6,17.46 \mathrm{mg} / \mathrm{l}$ phenylmethyl sulphonyl fluoride) to a concentration of $10 \mathrm{mg} / \mathrm{ml}$. Aliquots of $300 \mu \mathrm{g}$ were pipetted into a 96 well microplate and the volume made up to $100 \mu \mathrm{l}$ with coating buffer. Incubation of 2 hours at $20^{\circ} \mathrm{C}$ and 16 hours at $4^{\circ} \mathrm{C}$ was followed by blotting and washing with TBS-T (10 mM TRIS-hydrochloride (Sigma), $140 \mathrm{mM} \mathrm{NaCl}, \mathrm{pH} 7.4)$. Wells were blocked with $1 \%$ bovine serum albumin (BSA) in TBS-T for 30 minutes at $20^{\circ} \mathrm{C}$ followed by further washing with TBS-T. Polyclonal rabbit anti-human L-ferritin (Sigma) was diluted $1 / 500$ in TBS-T and $100 \mu \mathrm{l}$ added to the wells for 90 minutes at $20^{\circ} \mathrm{C}$. Washing with TBS-T was followed by the addition of $100 \mu \mathrm{l}$ of a $1 / 500$ dilution in TBS-T of monoclonal anti-rabbit IgG (clone RG-96) alkaline phosphatase conjugate (Sigma) for 90 minutes at room temperature. Wells were again washed in TBS-T and $50 \mu \mathrm{l}$ of Sigma 104 phosphatase substrate and colour reagent in colour development solution ( $100 \mathrm{mM}$ TRIS, $100 \mathrm{mM} \mathrm{NaCl}$, $5 \mathrm{mM}$ magnesium chloride (Sigma) added for 20 minutes. A volume of $50 \mu \mathrm{l}$ of $0.1 \mathrm{M} \mathrm{NaOH}$ was added followed by plate reading at 405 $\mathrm{nm}$. Control and subject lens homogenates were subjected to four separate analyses and were compared to ferritin standards from 13.6 ng to $64 \mathrm{ng}$ (horse spleen ferritin).

\section{HISTOLOGICAL ANALYSIS}

A small portion of lens was placed in glutaraldehyde for electron microscopy, post-fixed in osmium tetroxide, and stained with lead acetate. Ultrathin sections were prepared from $1 \mathrm{~mm}$ blocks and viewed under a Jeol 1010 transmission electron microscope. The remaining material was processed through to paraffin wax and $5 \mu \mathrm{m}$ sections cut for histopathology and immunohistochemistry. Sections were microwaved in citrate buffer $\mathrm{pH}$ 6.0 , stained with haematoxylin and eosin, periodic acid Schiff, and van Gieson stains. Immunohistochemistry was performed using monoclonal antibodies to L-ferritin and $\mathrm{H}$-ferritin (gift from Dr P Arosio, Milan, Italy), diluted 1:50, and sections incubated for 1 hour in TRIS buffered saline. The presence of bound antibody was detected using an streptavidin-biotin (ABC) kit (Dako Ltd) according to the manufacturer's instructions. Diaminobenzidine was used to detect the presence of peroxidase labelled bound antibody.

\section{Results}

L-ferritin ELISA of freeze dried lens showed mean L-ferritin content of $147 \mu \mathrm{g} / \mathrm{g}$ dry weight of lens (range 108-201 $\mu \mathrm{g} / \mathrm{g}$ ). The control lenses had no detectable L-ferritin by this assay $(<16 \mu \mathrm{g} / \mathrm{g})$.

On light microscopy, the lens opacities appeared as amorphous poorly eosinophilic deposits scattered throughout the lens stroma. With monoclonal anti-L-ferritin there was dense staining of the deposits (Fig 2A). With monoclonal anti-H-ferritin staining was absent from both the lens stroma and deposits (Fig
L-FERRITIN ELISA

Unfixed lens samples were stored at $-20^{\circ} \mathrm{C}$ until freeze drying and homogenisation in 
2B). Electron microscopy showed these deposits to be square crystalline inclusions within the lens stroma (Fig 2C).

\section{Discussion}

This report provides the first comprehensive analysis of the lens in HHCS. It demonstrates that increased immunoreactive L-ferritin within the lens is associated with crystalline deposits composed, at least in part, of L-ferritin. Cataract is the only demonstrable clinical abnormality in HHCS and our findings indicate a unique mechanism of cataract formation.

In humans, synthesis of the ferritins is ubiquitous ${ }^{2}$ and regulation by the iron dependent IRE-IRP system is widespread. The rate of synthesis of ferritin in cultured canine lens epithelial cells depends on iron availability and redox conditions ${ }^{9}$ suggesting that the lens epithelium also has a functional IRE-IRP system. Although ferritin synthesis in the normal lens is closely regulated ${ }^{10}$ in HHCS, the lens epithelium may synthesise increased quantities of L-ferritin independently as occurs in cultured human lymphoblasts. ${ }^{41}$ This study supports this suggestion by demonstrating that $\mathrm{L}$-ferritin was undetectable in the control lens and that there was no demonstrable staining of the lens stroma in the HHCS lens with anti-Hferritin. In contrast, the L-ferritin concentration was greatly increased in the HHCS lens. Further evidence of a dramatic and selective increase in L-ferritin synthesis in this disorder is provided by a previous analysis of a homogenised HHCS lens extracted by phacoemulsification. ${ }^{11}$

Even small quantities of ferritin in the normal lens may, through its ability to sequester free iron, limit oxidative damage to lens proteins from the iron catalysed generation of free radicals. It has been proposed that excessive production of L-ferrtin in the HHCS lens may disrupt this mechanism and that cataracts are the result of subsequent oxidative damage. ${ }^{11}$ The histological findings presented here indicate that oxidative damage is unlikely to be the explanation in this case. The lens opacities appear to result directly from aggregates of L-ferritin rich material with crystalline structure. Our findings do not completely disprove the oxidative hypothesis as the excess of a pure L-ferritin aggregate might bind iron inefficiently. However, even if this were so the lens fibre cells have a very low oxygen tension, so that if defective iron binding occurred in these patients the problem would be much more likely to manifest itself in oxygen rich tissues and certainly not in the lens. The observation is that cataract is the only clinical feature of HHCS.

Although the lens is not the only tissue in patients with HHCS to synthesise increased quantities of L-ferritin, it is uncertain whether the lens is alone in its ability to acquire aggregates of L-ferritin. Detailed ultrastructural analysis of other tissues in HHCS has not been performed although in peripheral blood, marrow, and liver biopsy material, there is no light microscopic evidence of intracellular inclusions. ${ }^{5}$ The presence of such unusual deposits appears unique to the lens and is likely to be a manifestation of the unique anatomical and biochemical properties of this tissue.

Ferritin polymers synthesised in vitro by HHCS lymphoblasts are a mixture of L-chain homopolymers or L-chain rich heteropolymers and are associated with only small quantities of iron. ${ }^{11}$ It is likely therefore that these abnormal polymers are cleared rapidly. The lens appears to be unusual in that the turnover of radiolabelled L-ferritin in cultured lens epithelium is very slow. ${ }^{9}$ It is possible that the lens acquires a higher load of L-ferritin in HHCS compared with other tissues simply because of its poor catabolic activity. Furthermore, L-ferritin deposits in the lens nucleus in HHCS, the only intact material available at cataract extraction, is likely to represent ferritin synthesised decades before the development of visual symptoms because proteins in this part of the lens are not renewed. ${ }^{12}$ When protein synthesis ceases in the maturing lens fibre an acquired ferritin load would be immortalised in the lens fibre.

Slow catabolic clearance of ferritin may not be the only explanation for cataract formation. One might speculate that the ferritin was soluble initially and did not scatter light unduly. With age the protein may have suffered post-translational modification, as happens to other proteins in the lens. ${ }^{13}$ Protein deposits are seen in a variety of diseases including amyloid diseases, prion diseases ${ }^{14}$ and in senile cataract. ${ }^{15}$ These are characterised by the presence of misfolded or unfolded protein. It is possible that slow post-translational modification of ferritin in the lens causes a conformational change to a form that aggregates. Alternatively the change in aggregation properties could be due to an alteration of the protein surface, analogous to the aggregation of haemoglobin S. The high molecular weight of L-ferritin aggregates may also be significant. Undesirable interactions between damaged or abnormal lens proteins are prevented by $\alpha$ crystallin acting as a molecular chaperone. ${ }^{16}{ }^{17}$ $\alpha$ Crystallin is a large protein with a central cavity. ${ }^{18}$ If protection is normally within the cavity, then ferritin molecules would be too big to be protected from detrimental external interactions especially as ferritin has a cavity of its own.

1 Ponka P, Beaumont C, Richardson DR. Function and regulation of transferrin and ferritin. Sem Haematol lation of tran

2 Woorwood $M$. Ferritin in human tissues and serum. Clin Haematol 1982;11:275-307.

3 Girelli D, Corrocher R, Bisceglia L, et al. Molecular basis for the recently described hereditary hyperferritinaemia cataract syndrome: a mutation in the iron-responsive element of ferritin L-subunit gene (the 'Verona mutation'). Blood 1995;86:4050-3.

4 Beaumont C, Leneuve P, Devaux I, et al. Mutation in the iron responsive element of the $\mathrm{L}$ ferritin mRNA in a family with dominant hyperferritinaemia and cataract. Nat Genet 1995;11:444-6.

5 Amold JD, Mumford AD, Lindsay JO, et al. Hyperferritinaemia in the absence of iron overload. Gut 1997;41:408-10.

6 Cazzola M, Bergamaschi B, Tonon L, et al. Hereditary hyperferritinaemia cataract syndrome: relationship between phenotypes and specific mutations in the ironresponsive element of ferritin light chain mRNA. Blood
1997;90:814-21. 
7 Mumford AD, Vulliamy T, Lindsay J, et al. Hereditary hyperferritinaemia cataract syndrome: two novel mutations in the L-ferritin

8 Blakytny R, Harding JJ. Prevention of cataract in diabetic rats by aspirin, paracetamol (acetaminophen) and ibuprofen. Exp Eye Res 1992;54:509-18.

9 Goralska M, Harned J, Fleisher LN, et al. The effects of ascorbic acid and ferric ammonium citrate on iron uptake an storage in lens epithelial cells. Exp Eye Res 1998;66:687-97.

$10 \mathrm{McG}$ ahan MC, Harned J, Grimes AM, et al. Regulation of ferritin level in cultured lens epithelial cells. Exp Eye Res 1994;59:551-5.

11 Levi S, Girelli D, Perrone F, et al. Analysis of ferritins in lymphoblastoid cell lines and in the lens of subjects with hereditary hyperferritinaemia cataract syndrome. Blood 1998;91:4180-7.
12 Harding JJ. Lens. In: JJ Harding, ed. Biochemistry of the eye. London: Chapman and Hall, 1997:94-143.

13 Harding JJ. Cataract: biochemistry, epidemiology and pharmacology. London: Chapman and Hall. 1991.

14 Carrell RW, Lomas DA. Conformational disease. Lancet 997;350:134-8.

15 Harding JJ. Cataract, Alzheimer's disease, and other conformational diseases. Curr Opin Ophthalmol 1998;9:10-13.

16 Horwitz J. Alpha crstallin can function as a molecular chaperone. Proc Natl Acad Sci 1992;89:10449-53.

17 Hook DWA, Harding JJ. Protection of enzymes by alpha-crystallin acting as a molecular chaperone. Int $\mathcal{F}$ Biol Macromol 1998;22:295-306.

18 Haley DA, Horwitz J, Stewart PL. The small heat-shock protein, $\alpha$-crystallin, has a variable quaternary structure. $\mathcal{F}$ Mol Biol 1998;277:27-35. 